\title{
An Enhanced Web Base Certificate Verification System
}

\author{
Izuchukwu Chijioke Emele, Stanley Ikechukwu Oguoma, Kanayo Kizito Uka, \\ Emeka Christian Nwaoha \\ Department of Computer Science, Imo State University (IMSU), Owerri, Nigeria \\ Email: chijiokeemele@gmail.com, oguomaikechukwu@gmail.com, kizzyict@gmail.com,christianemeka15@gmail.com
}

How to cite this paper: Emele, I.C., Oguoma, S.I., Uka, K.K. and Nwaoha, E.C. (2020) An Enhanced Web Base Certificate Verification System. Open Access Library Journal, 7: e6342.

https://doi.org/10.4236/oalib.1106342

Received: April 21, 2020

Accepted: July 27, 2020

Published: July 30, 2020

Copyright $\odot 2020$ by author(s) and Open Access Library Inc.

This work is licensed under the Creative Commons Attribution International License (CC BY 4.0).

http://creativecommons.org/licenses/by/4.0/

\begin{abstract}
The objective of this work is to design and implement an enhanced wed-based certificate verification system that will assist schools and co-operate organizations to confirm the originality of students' certificate by displaying certificate details, and format with owner's image. This work was motivated by the level of certificate forgery, time wastage and the stress encountered while processing this manually. The system adopted the object oriented and design methodology (OOADM) while the programming language used for the front-end design was Hypertext Markup Language (HTML5), Cascading Style Sheet (CSS3), Bootstrap Frame work and Back end design was achieved with Hypertext Preprocessor (PHP5) and My-Structural Query Language (MySQL). The result after design was an enhanced web-based certificate verification system that was able to verify and authenticate students' certificates and display certificate image after verification process, which could be used to reduce the high rate of certificate forgery not only within the educational system but in other co-operate organizations.
\end{abstract}

\section{Subject Areas}

Information Management Technology (IMT) and Security

\section{Keywords}

Web Base, Verification System, Certificate Identification, Registration

\section{Introduction}

Verification is the process of checking the accuracy of the information given by clients seeking services from a Social Enterprise organization. According to Wikipedia Certification refers to the confirmation of certain characteristics of an object, person, or organization. This confirmation is often, but not always, pro- 
vided by some form of external review, education, assessment, or audit. Accreditation is a specific organization's process of certification. The Internet has been one of the most frequently used means of exchanging information among people [1]. The rapid increase in the volume of scientific literature has led to researchers constantly fighting information overload in their pursuit of knowledge.

Furthermore, everyone should be able to browse the same websites and have the opportunity for equal user experience on the Internet. In other words, the Internet should be usable by everyone. Most of employees falsify their educational certificates. What's more, industry, organization, firm, experts cite academic fraud as the most common lie on resumes. By this organizations are prone to danger or harm. This has been accelerated by employees who falsify the information. The risks involved of not verifying applicants' includes, greater recruiting and replacement costs, increased employee turnover, compromised business performance, embarrassment and negative impact on your organization's reputation, declining market value, cost customers and revenue and civil and criminal liability, etc.

Globally, greater percentage of the organizations, firms industries rely on the use of paper verification methods, which happens to be the traditional method to verify the documents presented to them. These organizations and institution do not have the capacity to verify the document presented to them instantly. One of the problems we have in traditional paper based is that people and especially recruiters and employers find difficult in knowing the validity of documents such as academic certificates presented to them because there is no way they can authenticate those documents instantly. In the current scenario most of the organization does not have the capacity to instantly authenticate the documents presented. Traditional identity information verification and validation processes were developed in a "paper" transaction world. Several studies have been made towards developing models to verify and authorize certificates in government sectors. According to International Journal of Advanced Technology \& Engineering Research (IJATER) Yogesh, et al. designed and developed a model to authorize certificates in government sectors using cloud computing environments. University of Grants Commission in India developed an e-certification/verification for online.

This disturbing decline in ethics, which touches everyone from recent graduates to seasoned executives, has serious implications for all organizations. Several actions can be taken by businesses to protect themselves. First, employers must independently check prospective employees' backgrounds. Second, those with questionable backgrounds or who lie on their resumes should be considered high fraud risk individuals. Third, every effort must be made to avoid hiring those with criminal backgrounds. The motivation came as a result of the problem of certification forgery and verification among our youths and even our leaders. The researcher saw this as a problem and now took initiative to come up with a prototype which when open to public can be used to solve the problem of verifying academic certificates of member of parliament and anybody wishing to verify in any country at large. To conquer and reduce this problem, there is need 
for a secure automated verification method. One of the existing methods is the accessing of documents online and verification and authenticity via a secure hosted website.

This paper proposes a model shown in Figure 1 for academic certification based on web environment. Here the application is placed or installed and hosted in the internet as an independent system not incorporated into any school portal, personal or organizational website rather as a website to verify and guarantee authenticity of certificates at various level. The system displays certificate details and format with user's image after verification processes are concluded. The web is chosen because it provides and delivers application via internet which is accessed from web browsers by using devices such as laptop, mobile, desktop, etc. User can access through online by using website tools or web browser. The database was hosted in the internet in which verifications of academic certificates can be instantly verified. To do this the researcher ensures that the data integrity and security is enhanced by adding an additional security technique both from client end and to administrative end.

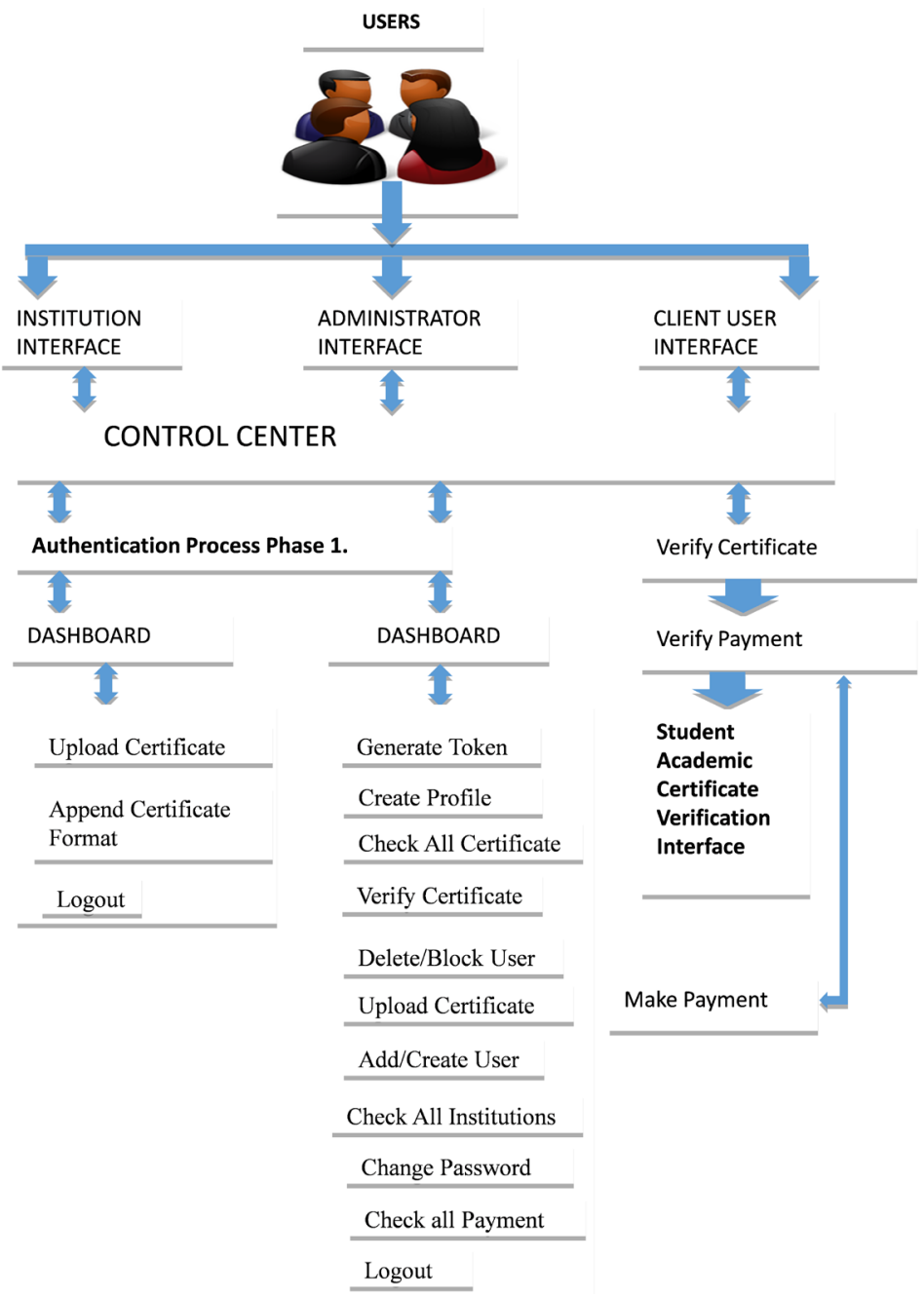

Figure 1. Enhanced web base certificate verification model. 


\subsection{Motivation}

Over the years there have been a great need for easy and fastened means to verify results/certificates to reduce the level or certificate forgery and to ease the stress and also save the time of certificate verification which is done manually today, an employer or anybody concern will have to come or send delegate to school to verify a particular certificate, some employer never did and this has resulted on accepting a forge certificate. The research was therefore motivated by this loop holes in various institutions and developed a system that will help solve these problem.

\subsection{Statement of Problem}

Verification of certificates is a major concern in organization, academic institutions, recruiters and employers. Employers have been experiencing high alarming rate of fake certificates. This is as result of production of fake certificates.

After careful studying and analyzing the present system, these problems were unavoidably identified.

1) There is always a time delay in the manual method of certificate verification.

2) Organizations and industries do not have easy and immediate access to present system.

3) Certification verification is not done instantly there by consuming time, this poses a difficulty in knowing the validity of an academic certificate.

4) Service Failure.

\subsection{Aim and Objectives}

The aim of this project is to design an enhanced wed based certificate verification system.

The objectives of the study are as follows:

1) To provides easy access for organizations to check for the validity of the certificate of their employees remotely.

2) To design a system that can help to minimize the high rate of manipulation and falsification of certificates in higher institutions.

\subsection{Significance of Study}

The significance of this study is to help and give a benefit to the student, staff, school management and anyone that wants to verify the authenticity of any certificate from the school. When this is achieved, the system will give institutions, recruiters and employers the opportunity to authenticate the certificate instantly. It will help reduce the stress in higher institution because of the manual methods its being done.

\section{Literature Review}

Academic affair is usually in charge of student result and up to date of the honors 
awarded to each students. It has a collection of sources, resources, and services, and the structure in which it is housed. There can be no doubt that much of the certificates in this area speculates on the future role of safe means (mini-library) none of which is particularly clear. [2], libraries have been seen as in danger of "substitution" The web is becoming "an ubiquitous source of information" giving an "illusion of depth and comprehensiveness" that leads to a questioning of the value of libraries and their collections.

Therefore this chapter involves the review and study of related literatures. In this work, an extensive research is done. The chapter covers detailed explanation and information on certificate verification processes, detailed definition and explanation of certification, characteristics of a web based application, users impact on web applications, different kinds of techniques in certificate verification, various technologies use in certificate verification, advantages and disadvantages of web applications, importance of certificate verification in higher institutions and organizations, benefits and functions of web based applications.

\section{Certificate and Certification}

Merriam-Webster dictionary stated that a document containing a certified statement especially as to the truth of something specifically:

a) A document certifying that one has fulfilled the requirements of and may practice in a field;

b) Something serving the same end as a certificate;

c) A document evidencing ownership or debt.

According to this dictionary, a certificate could be a document indicating a true identification/validation to a statement made towards someone.

\section{Certification}

[3] highlighted that information technology as in other fields such as teaching, accounting, and acupuncture; certification is a formal process of making certain that an individual is qualified in terms of particular knowledge or skills. Certification programs are often fostered or supervised by some certifying agency, such as a professional association.

Wikipedia defined certification as the confirmation of certain characteristics of an object, person, or organization. This confirmation is often, but not always, provided by some form of external review, education, assessment, or audit. Accreditation is a specific organization's process of certification.

Certification does not designate that a person has sufficient knowledge in a subject area, only that they passed the test. Certification does not refer to the state of legally being able to practice or work in a profession.

\section{Verification}

Verification is intended to check that a product, service, or system (or portion thereof, or set thereof) meets a set of design specifications [4]. In the development phase, verification procedures involve performing special tests to model or 
simulate a portion, or the entirety, of a product, service or system, then performing a review or analysis of the modeling results. In the post-development phase, verification procedures involve regularly repeating tests devised specifically to ensure that the product, service, or system continues to meet the initial design requirements, specifications, and regulations as time progresses [4]. It is a process that is used to evaluate whether a product, service, or system complies with regulations, specifications, or conditions imposed at the start of a development phase. Verification can be in development, scale-up, or production. This is often an internal process [5].

\section{Methodology}

A research methodology defines what the activity of research is, how to proceed, how to measure progress and what constitutes success. It can be defined as the analysis of the principles of methods, rules and postulates employed by a discipline. Methodology adopted in this work is object-oriented analysis and design methodology (OOADM). Object Oriented Analysis and Design Methodology (OOADM) is a popular technical approach for analyzing and designing an application, system and business by applying object-oriented programming as well as using visual modeling throughout the development life cycle to foster better stakeholder communication and product quality. OOADM is software approaches that models and design a system. It is also applied in the phases of software development life cycle (analysis, design and implementation).

\subsection{Proposed System Model}

The proposed system model has three users, activities and privileges shown in Figure 1. As illustrated in Figure 1, every access to the new system must undergo authentication process before accessing the dashboard. The model contained block of activities each user would perform, interfaces for authentication, certificate verification, payment and upload. As stated at the introduction of this paper, this work is structured or planned to enable remote integration of numerous institutions and organizations to achieve one goal, which is to fight against fake certificate hence to restore sanity in service delivery. Figure 1 presents a clear picture of such system, where both public and private organizations can confine in getting secured information on their employees academic qualifications.

\subsection{Analysis of the Existing System}

The existing system of certificate verification is done differently by various organizations; some are done manually while some are done via the organization portal. But either online or manual certificate verification process, the problem remains availability and accessibility. It is not every institution has a certificate verification portal and also not all private or public organization has so the existing system lacks collective integration and hence this makes it difficult to provide firsthand information on candidate's academic qualification. 
Therefore the existing process of certificate verification adopted by most institutions or organization is manual shown in Figure 2, where candidate are asked to send in their original Certificate, after receiving from Candidate, the organization will Ask the University of the candidate to forward a confirmation letter indicating if the candidate was actually a graduate of the institution. This confirmation letter will contain the candidate names, matriculation number, faculty, department, and year of entry, year of graduation, certificate number and class of degree among others. Sometimes, the organization could send their staff to visit the school of the candidate for an enquiry or send in third party investigation (Agency) for information.

Certificate verification through Organization website, this process is limited because is not all academic institutions are connected to their services, therefore their certificate verification process will only provide certificate details but cannot shown the certificate image format, so hence the certificate information provided by such organizations are not $100 \%$ authentic because manipulation and falsification can still be identified.

\subsection{Analysis and Operation of the New System}

The operation of the new web based certificate verification system works in a way that protects unauthorized persons both from the organization and the various institutions that partner with them. It has different modules with both the institution login and organization login is the main module and method of access. As shown in Figure 3 the various user case of all the users of the new system are fully illustrated while Figure 4 and Figure 5 shows the various sequence diagram of the entire system. The new system uses the class diagram as shown in Figure 6 to further provide a clear understanding of the operations of the new system, modules and sub-modules relationships. The new system has a control center shown in Figure 7 where access to other modules in the new system could be accessed once a user clicks on the "verify your certificate button" Figure 8 on the Control center which immediately launches the certificate verification process module shown in Figure 9.

The institution profile account creation is done by the representative of the institution and the user must provide valid details like username, password, and a secret pin called (TOKEN) which only authorized user could have access to and will be generated by the organization. After account filling, a link will be sent to the users email to complete the registration and to maintain security of the platform. It is the email link sent to the account the user could use to access or enter into the dashboard shown in Figure 10, where data/certificate upload shown in Figure 11 and, upload of certificate image format could be achieved. As a centralized database system, the entire operations are managed by the system administrator shown in Figure 12 of this work. The Users Profile Creation Interface shown in Figure 13 as stated is used to register new institution users on the platform and it is through this means that activities of various users could be tracked in case of any misconduct. 
Payment module shown in Figure 14 is use to make payment for clients certificates to be verified.

When payments are made using this module, a confirmation message is sent to users email.

Verify module will be used to verify the certificate once payment is made, the necessary requirement (cert number and full name) will be needed for the verification to scale through.

Institution login module could be accessed through the provision of a valid username and the secret token issued doing account generation stage shown in Figure 15. After verification of the login token and pin is done, the system will direct the user into the certificate upload module shown in Figure 11.

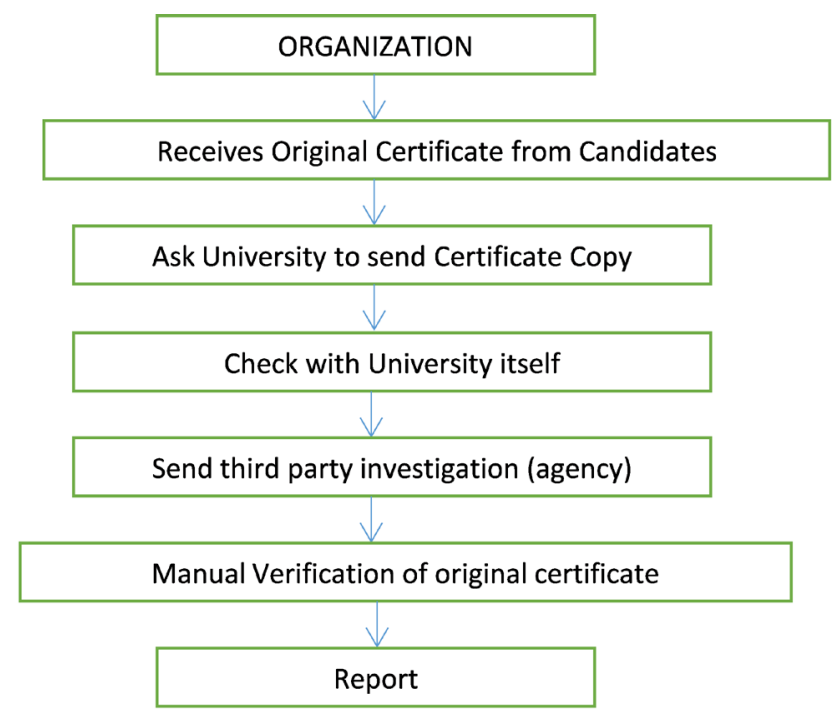

Figure 2. Manual diagram showing the analysis of the existing system.

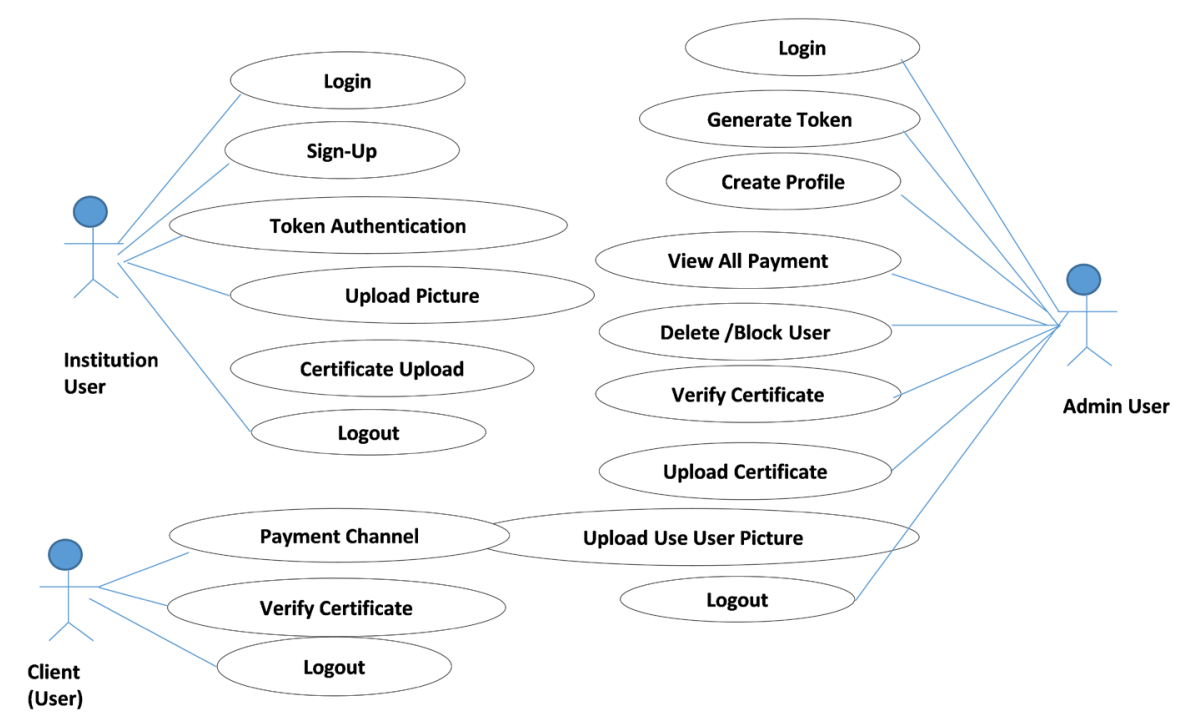

Figure 3. Use case diagram of new system. 


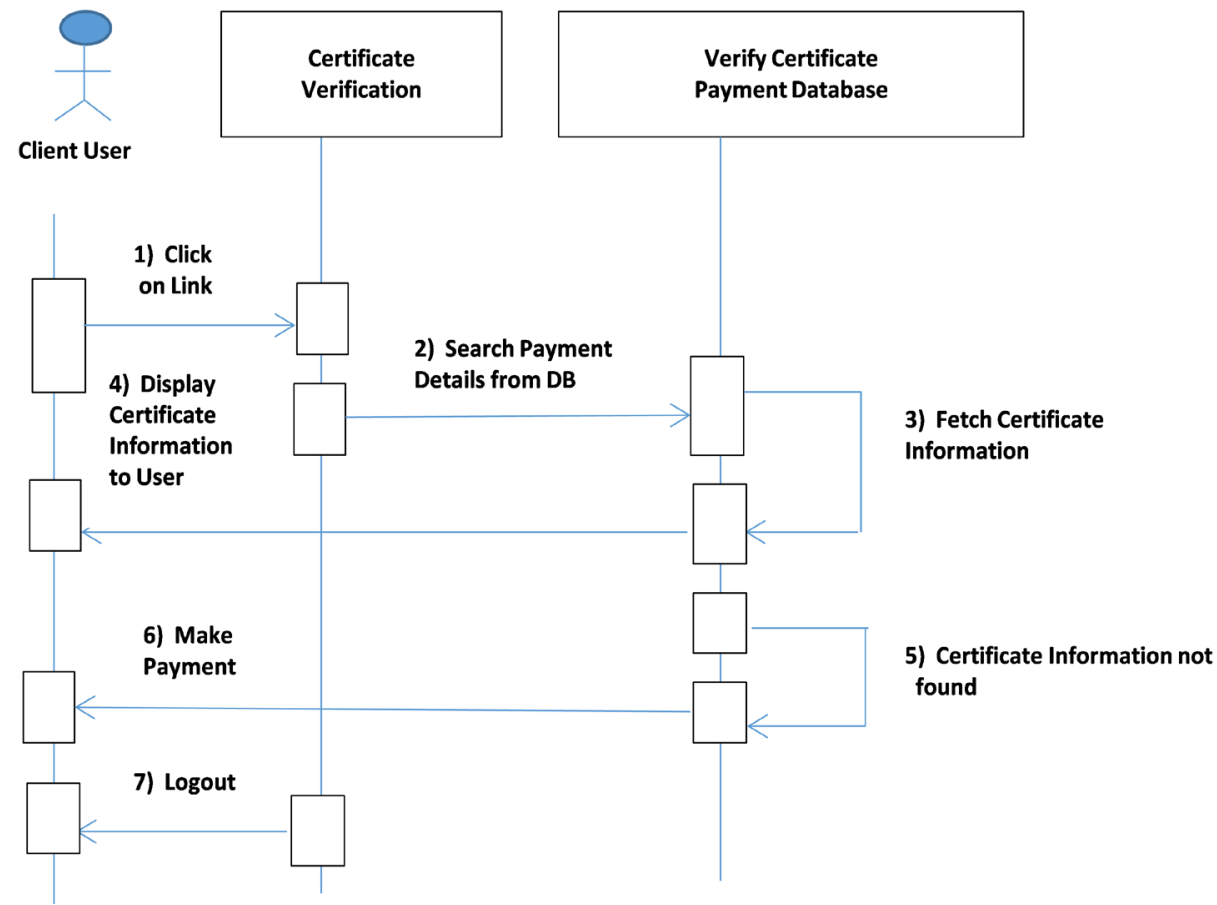

Figure 4. Sequence diagram of the new system certificate verification process.

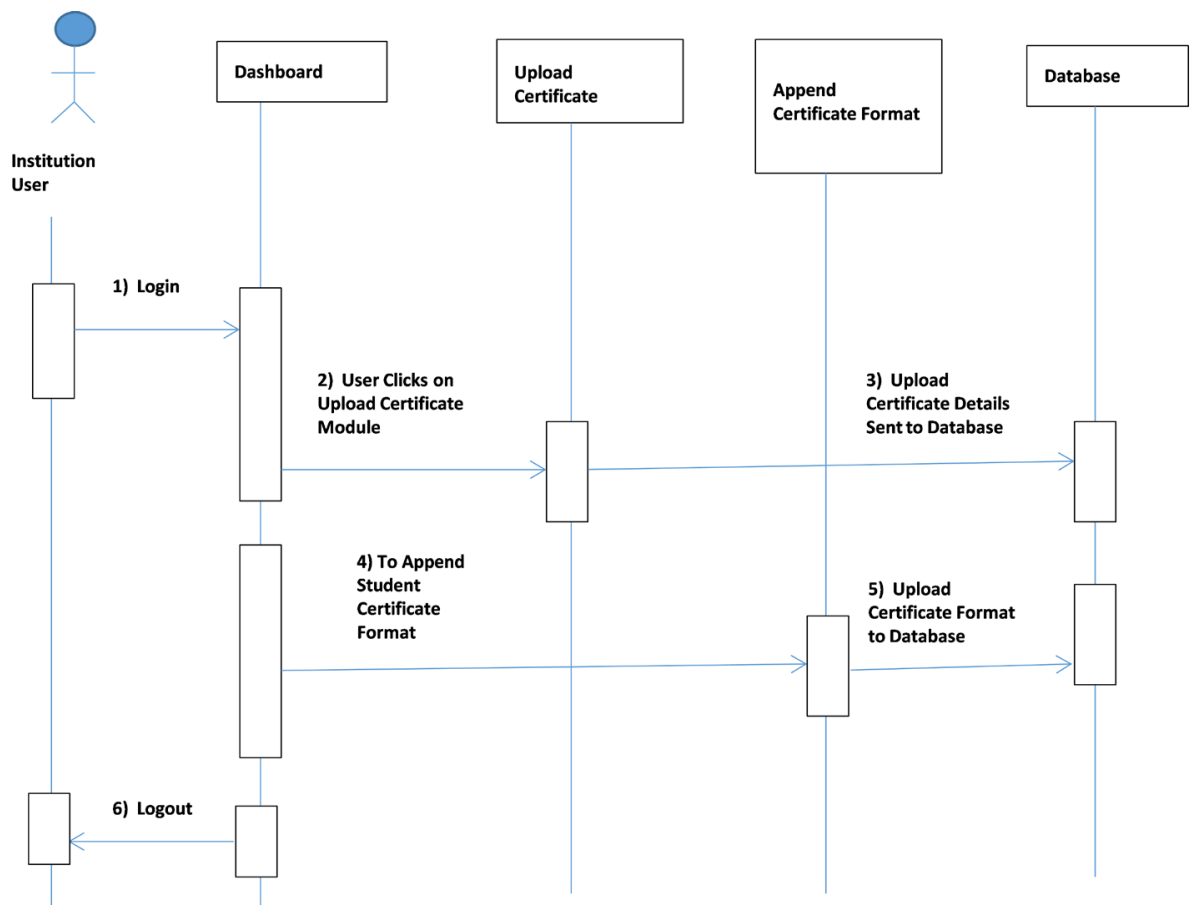

Figure 5. Sequence diagram of the institution user.

The Admin module shown in Figure 12 is in charge of the entire system operations which include: granting privilege to users, creating new users, creation of profile page for institutions, generation of the secret token, changing password, updating of records, viewing of all reported and affiliated institutions and to ensure that only valid and recognized institutions have access to the platform. 


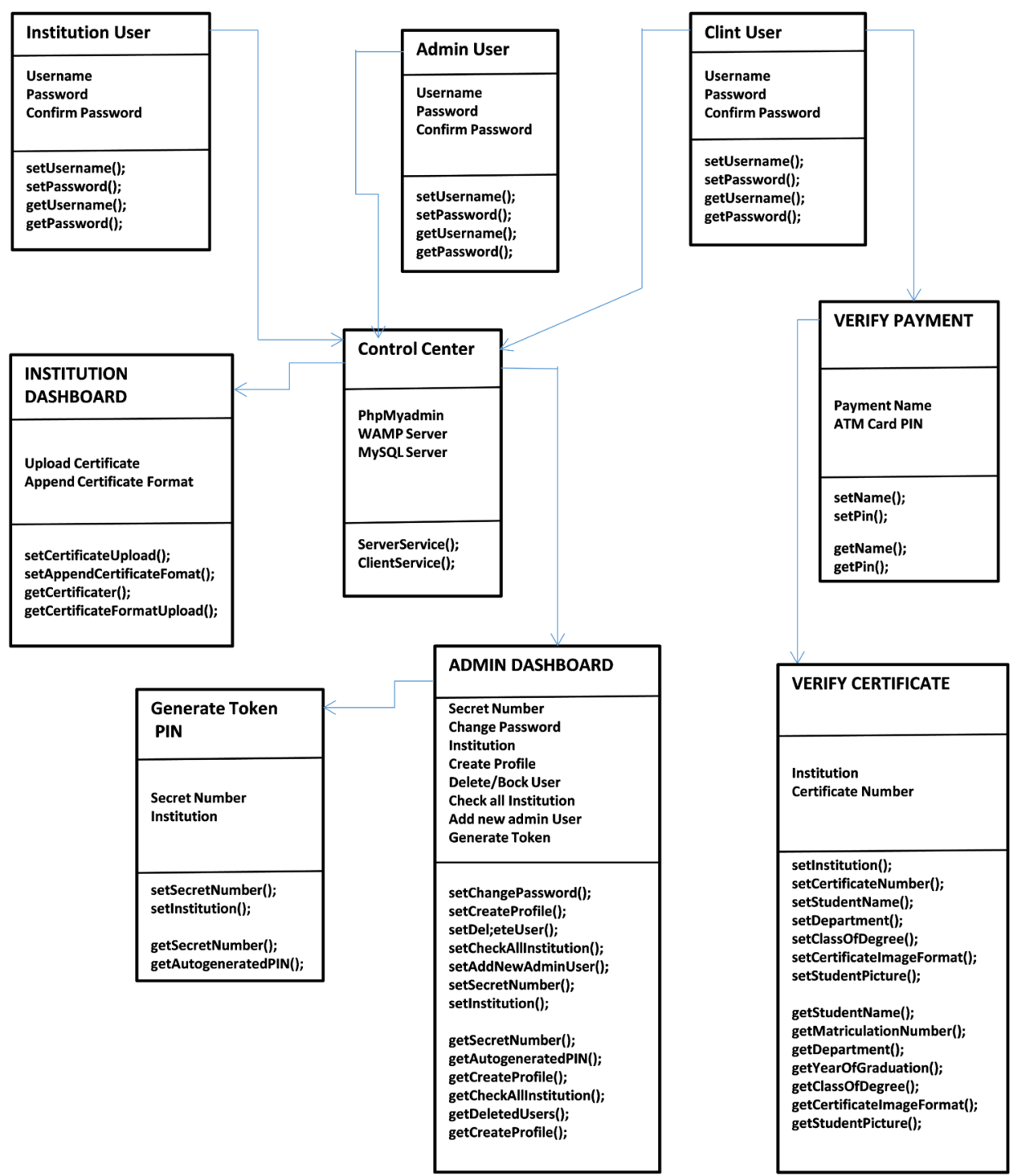

Figure 6. Class diagram of the new system.

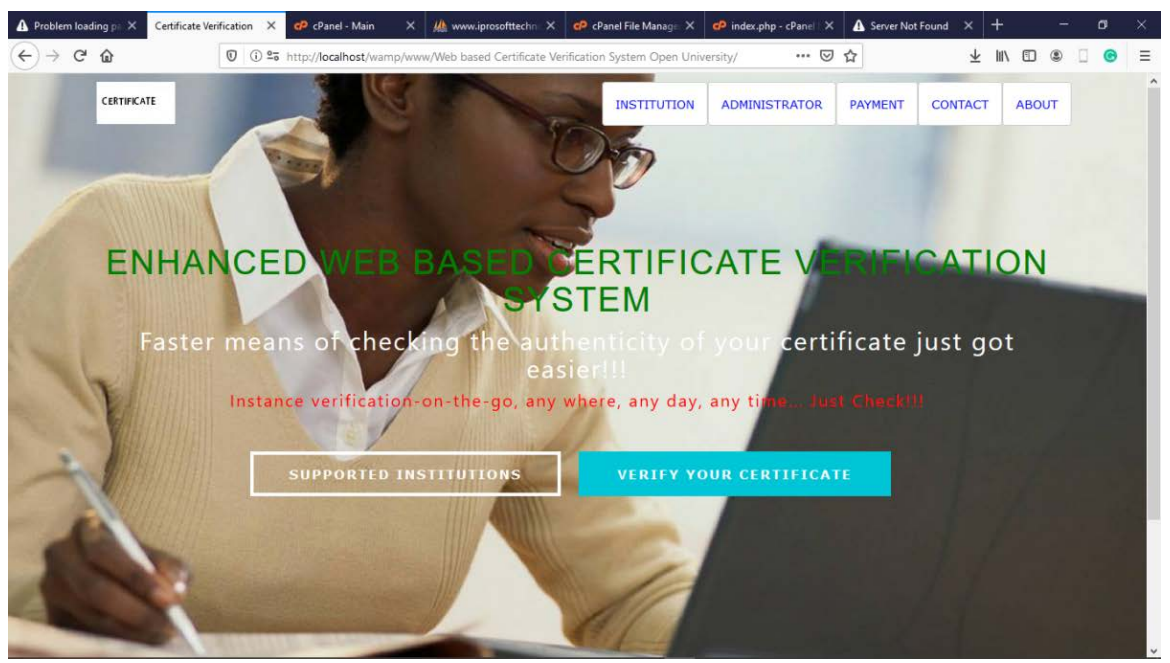

Figure 7. Control center interface. 


\subsubsection{Certificate Verification Process}

Once user clicks on the verify certificate button, a window pops up shown in Figure 8 . This window will ask user verify certificate payment by entering payment name and ATM card PIN, then by clicking on the button "PROCEED TO CERTIFICATE VERIFICATION" the interface for candidate certificate verification will be displayed. The certificate verification module shown in Figure 9

\section{VERIFY CERTIFICATE PAYMENT}

$\times$

PAYMENT FULLNAME:

Enter Your Payment Name

ATM CARD PIN

Enter Your ATM Number

PROCEED TO CERTIFICATE VERIFICATION

Figure 8. Certificate payment verification interface.

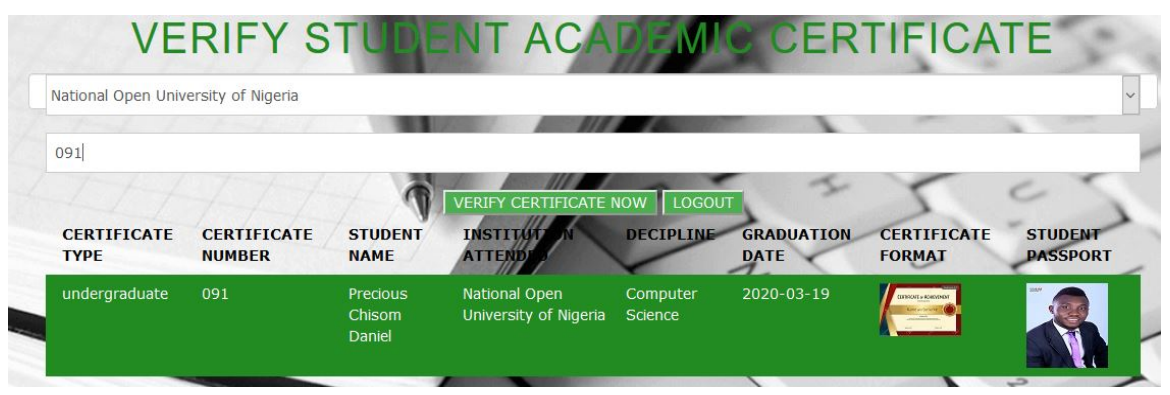

Figure 9. Certificate verification interface.

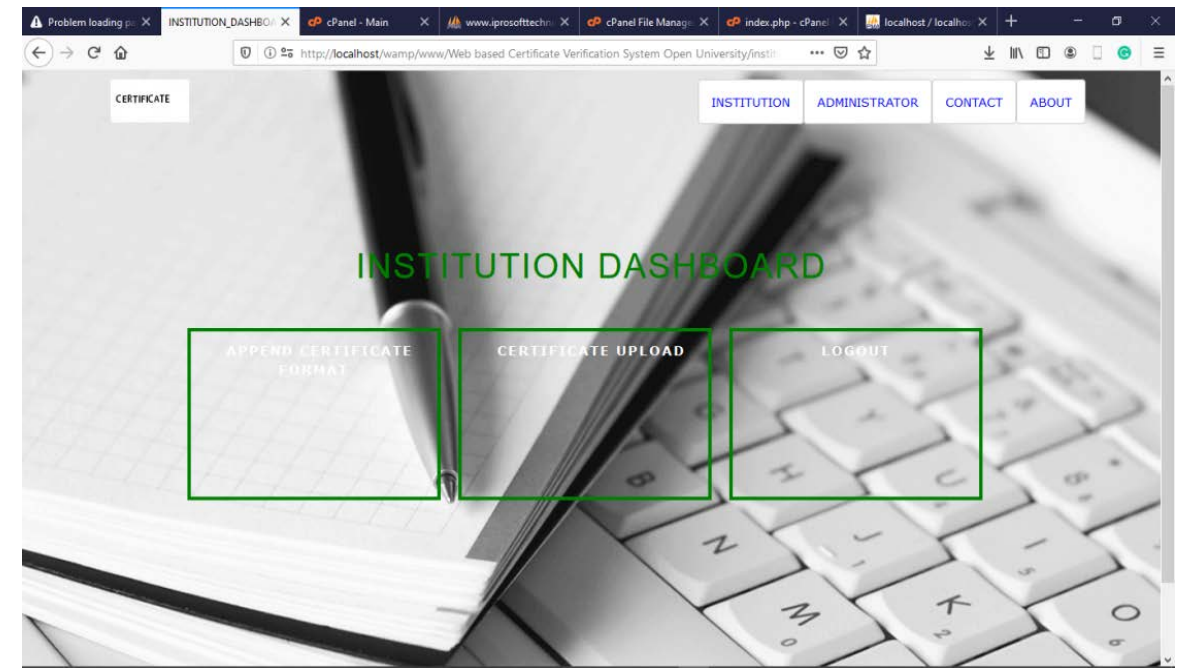

Figure 10. Institution dashboard interface. 


\begin{tabular}{|c|c|}
\hline FULLNAME: & EMAIL ADDRESS \\
\hline Enter Your Fullname & Enter Your Email Address \\
\hline PHONE: & INSTITUTION \\
\hline Enter Your Phone Number & Enter Your Name of Institution \\
\hline INSIITUTION TOKEN: & CERTIFICATE NUMBER \\
\hline Enter Your Token & Enter Certificate Registration Number \\
\hline CERTIFICATE NAME: & STUDENT NAME \\
\hline Enter Certificate Name & Enter Your Name on Certificate \\
\hline UPLOAD SCAN CERTIFICATE: & UPLOAD STUDENT PICTURE \\
\hline Browse... No file selected. & Browse... No file selected. \\
\hline
\end{tabular}

Figure 11. Institution user certificate upload interface.

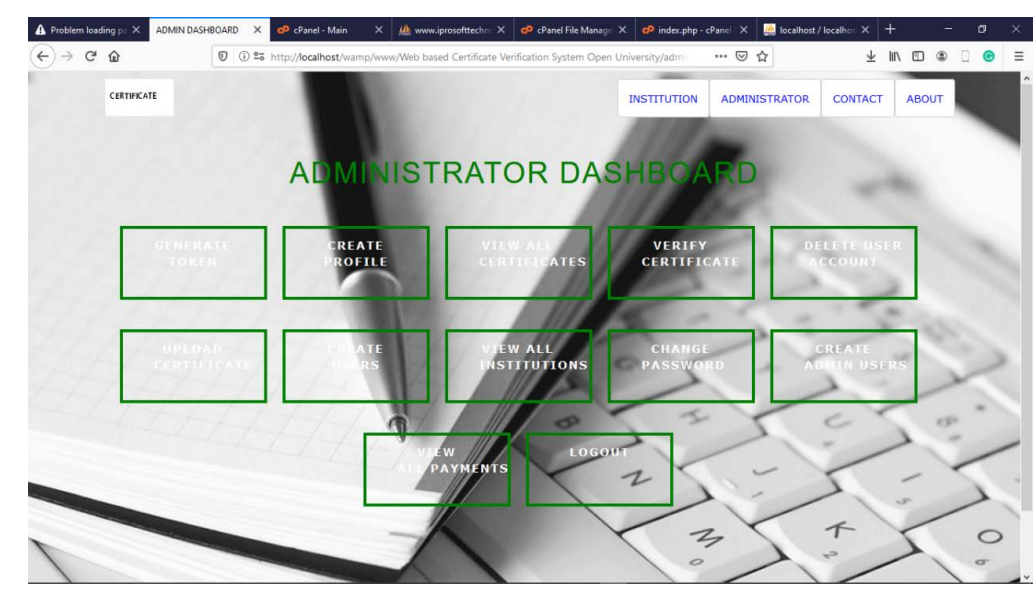

Figure 12. Administrator dashboard interface.

\section{CREATE PROFILE MODULE}

\begin{tabular}{|l|l|}
\hline & \\
\hline EULLNAME: & EMAIL ADDRESS:* \\
\hline Enter Your Fullname & Enter Your Email Address \\
\hline PHONE:* & INSTITUTION:* \\
\hline Enter Your Phone Number & Enter Your Name of Institution \\
\hline STAFF ID NUMBER:* & DEPARTMENT:* \\
\hline Enter Your Staff ID Number & Enter Your Department \\
\hline PASSPORT:* & DATE: * \\
\hline Browse... No file selected. & mm / dd / yyyy \\
\hline
\end{tabular}

Figure 13. Users profile creation interface. 


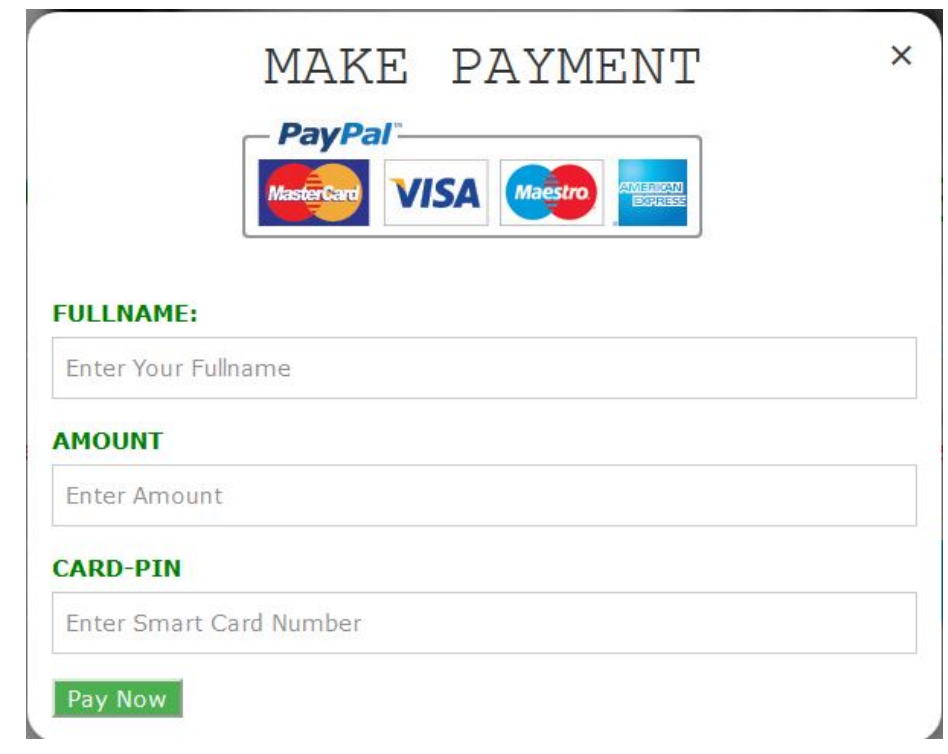

Figure 14. Certificate payment interface.

\section{GENERATE TOKEN}

PERSONAL NUMBER:

Enter Any Four Number

Your Token is: e55abafa1f77101102345

\section{GENERATE NOW}

Figure 15. Token Pin generation interface.

require user to provide the name of institution on the certificate and the certificate number before verification. The sequence diagram shown in Figure 4 explains in details the activities of the certificate verification interface and the User of the system while Figure 5 represents the sequence diagram of the institution user on the new system.

\subsubsection{Use Case Diagram of the New System}

A use case provides the actors on a system and their various privileges. These actors in this case are Student (Client Users), Institution Users and the Administrator User whose activities are provided based on their different roles in the new system. Figure 3 illustrates the various user cases of all the users of the new system.

\subsubsection{Sequence Diagram of the New System}

The process of the certificate verification system shown in Figure 4 above enable access to users on the platform but first the platform first verify if payment has 
been made for the transaction to proceed, if yes the details of the certificate is displayed to the user indicating certificate number, image, and students full name and matriculation number. Else the payment module will pop up to enable user make payment before the certificate information is provided on the screen. After a successive searching from the database and certificate number did not match any in the database, the system will display an error message to the user.

Sequence diagram of the institution user is shown in Figure 5 it contains the user dashboard where major activities after successful login into the platform is done. The institution user upload certificate of their students after approval by the school senate, append certificate format depending change and perform further activities on the database as required.

\subsubsection{Class Diagram of the New System}

The class diagram of the new system shown in Figure 6 contained the static view of the entire system. It is a collection of all the interfaces, classes, methods (Subroutine), associations and collaborations of various object member of the system. The class diagram makes it easier for a clear understanding of the operations of the new system, modules and sub-modules relationships.

It is used because of the adopted methodology, the methodology (OOADM) sees each entity in the system as an object, and hence ensures that each object behavior is contained in the program coding.

\section{Result}

There is no computer based software that does not have a control center. It is at the control center that every other modules or interfaces of the entire system are linked to. Some software designers call it Application Home or main activity. Therefore the Figure 7 above shows the new system control center.

Figure 8 above present the users certificate payment verification interface. It is launched immediately a user clicks on the "verify your certificate button" on the Control center.

\section{Conclusion}

Enhance web-based certificate verification system will be a useful research tool that will not only open up new techniques for verifying and confirming certificates before accepting it but rather encourage originality and confidence to organizations. With the full implementation of this new system, Corporate organizations, individual, academic institutions and government can now verify any certificate issued to persons without prior consultation of the institution that issued it. Once the institution is registered with the organization that owns this software it can be easily verified. For instance, "JAMB" schools registered with JAMB have access to some activities on the JAMB portal. Therefore this Enhance web based certificate verification system is designed to be an integrator between Candidates, institutions and employers. The new system was archived, and it saves time and reduces errors to its minimum level as compare with manual approach 
which have limiting point. In order to utilize information, it must be accessible. Accessibility includes both documentation of available data and tools for accessing the data. Enhance web based certificate verification system provides a tool that can assist with the documentation of online database connectivity and with the retrieval of the information. Enhance Web based certificate verification system offers convenience to the users and considerable ease to employers as they can authenticate certificate from school easily and more quickly than conventional methods of manual verification.

\section{Recommendation}

Based on experience during the research, the researcher would like to recommend that more research be done in certification verification and a lot of literature review done for related work. After successfully implementing and testing the prototype, in order to realize the intended purpose of the study the researcher recommends the prototype to be adopted by various institutions, private and public Organizations and the government as a centralized software for both local and international certificate verification system.

\section{Conflicts of Interest}

The authors declare no conflicts of interest regarding the publication of this paper.

\section{References}

[1] Lawrence, S., Giles, L. and Bollacker, K. (1999). http://citeseerx.ist.psu.edu/viewdoc/summary?doi=10.1.1.94.3109

[2] Carol, T., Pollard, R. and Wang, P.L. (2003) Increasing Effective Student Use of the Scientific Journal Literature.

[3] Rouse, M. (2006) Definition of Certification. https://whatis.techtarget.com/definition/certification

[4] ISO/IEC/IEEE (2010) ISO/IEC/IEEE International Standard-Systems and Software Engineering-Vocabulary 24765(E). Verification 5: Product, Service, or System Complies with a Regulation, Requirement, Specification, or Imposed Condition.

[5] Tran, E. (1999) Verification.

https://users.ece.cmu.edu/ koopman/des_s99/verification/ 